Article

\title{
Optical Properties of Au-Based and Pt-Based Alloys for Infrared Device Applications: A Combined First Principle and Electromagnetic Simulation Study
}

\author{
Min-Hsueh Chiu ${ }^{1}$, Jia-Han $\mathrm{Li}^{1}{ }^{1, *}$ and Tadaaki Nagao ${ }^{2,3, *}$ \\ 1 Department of Engineering Science and Ocean Engineering, National Taiwan University, No. 1, Sec. 4, \\ Roosevelt Rd., Taipei 10607, Taiwan; peter810601@gmail.com \\ 2 International Center for Materials Nanoarchitectonics (WPI-MANA), National Institute for Materials \\ Science (NIMS), 1-1 Namiki, Tsukuba, Ibaraki 305-0044, Japan \\ 3 Department of Condensed Matter Physics Graduate School of Science, Hokkaido University, \\ Kita-10 Nishi-8 Kita-ku, Sapporo 060-0810, Japan \\ * Correspondence: jiahan@ntu.edu.tw (J.-H.L.); NAGAO.Tadaaki@nims.go.jp (T.N.)
}

Received: 28 December 2018; Accepted: 15 January 2019; Published: 20 January 2019

\begin{abstract}
Due to the rapid progress in MEMS-based infrared emitters and sensors, strong demand exists for suitable plasmonic materials for such microdevices. We examine the possibility of achieving this goal by alloying other metals with the noble metals $\mathrm{Au}$ and $\mathrm{Pt}$, which have some drawbacks, such as low melting point, structural instability, and high costs. The six different metals (Ir, Mo, $\mathrm{Ni}, \mathrm{Pb}, \mathrm{Ta}$, and $\mathrm{W}$ ) which possess good properties for heat resistance, stability, and magnetism are mixed with noble metals to improve the properties. The optical properties are calculated by density functional theory and they are used for further investigations of the optical responses of alloy nanorods. The results show that the studied alloy nanorods have wavelength selective properties and can be useful for infrared devices and systems.
\end{abstract}

Keywords: alloy; infrared device; gold; platinum; permittivity; quality factor; first principle

\section{Introduction}

According to Planck's law, the thermal radiation of an ideal black body depends only on its temperature. However, in general, the thermal emissions from realistic objects differ substantially depending on their dielectric response and surface morphologies. Theoretical study and engineering designs of thermal emission devices are not only important in thermal emitters and infrared sensors but also useful for MEMS-based systems and micromachines. Therefore, some researchers are aiming to artificially tailor the emission spectrum by selecting the constituent materials and rationally designing their surface nanostructures to utilize thermal energy and heat management in a more efficient manner. For example, Dao et al. [1] demonstrated mid-infrared metamaterial perfect absorbers by using $\mathrm{Al}-\mathrm{Al}_{2} \mathrm{O}_{3}-\mathrm{Al}$ tri-layers structure, which an exhibited excellent absorptivity of $98 \%$ and a flexible wavelength selective response in the infrared region tuned by the disk diameter. They also demonstrated that the sharpness of the emission peak of the device, which only uses inexpensive industrial material, was comparable to that of absorbers composed of gold or silver. Yang et al. [2] applied four elemental metals $(\mathrm{Al}, \mathrm{Au}, \mathrm{Mo}, \mathrm{W})$ to realize a Tamm plasmon polariton to achieve a narrow band thermal emission, which may efficiently confine the energy and result in a sharp peak in absorption spectrum in the infrared region. Yokoyama et al. [3] achieved high emission intensity by developing a thermal emitter operative at very high temperature of $1000{ }^{\circ} \mathrm{C}$ using refractive molybdenum and aluminum oxide in a metal-insulator-metal structure. Both reported the wavelength selective characteristics by adequately selecting the material and structural parameter, to achieve higher 
device performance in the infrared region. Regarding the operation temperature, it is an important factor which may cause the degradation of material and damage to the devices. Therefore, exploring new refractory materials is expected to bring about greater potential to work in high-temperature environments. TiN thin film has suitable plasmonic properties similar to Au as well as a substantially high thermal stability up to about $500^{\circ} \mathrm{C}$ [4]. Kaur et al. [5] combined TiN nanoparticles and transparent ceramic microfiber wools to efficiently desalinate water by the broadband photothermal heat generation by absorbing ultraviolet to near-infrared light. Sugavaneshwar et al. [6] demonstrated high-quality TiN film on a flexible polymer film at room temperature, and illustrated the better and swifter conversion from light to heat energy in the infrared region.

On the other hand, due to the strong transmission and low hazard of infrared light to the living body, it is used for non-destructive sensing applications. For example, surface-enhanced Raman spectroscopy (SERS) is a technique widely used detection and sensing microdevices. With localized surface plasmons, Bansal et al. [7] simulated the effects of scattering efficiencies on the different shapes of $\mathrm{Ag}-\mathrm{Cu}$ alloy, such as sphere, cube, and nanobar with an effective radius $50 \mathrm{~nm}$. Dodson et al. [8] adjusted the gap between bowties to be $10 \mathrm{~nm}$ to pursue an extremely high enhancement factor. The effects of amplifying the electric field can be utilized in a sparse solution. The object in sparse solution can be concentrated with magnetic nanoparticles by applying the magnetic field, which reinforces the sensing efficiency. Brullot et al. [9] simulated and discussed the relations between the structure, size, and optical properties of magnetite-core gold-shell nanoparticles. They developed the comprehensive mechanism for designing the core-shell nanoparticles in the near-infrared light region. Kwizera et al. [10] successfully synthesized different shapes (sphere, popcorn, and star) and sizes of iron-oxide-core and gold-shell nanoparticles. The optical and magnetic properties of nanoparticles that may be exploited in different applications have been demonstrated. Liu et al. [11] synthesized urchin-like Ag-coated Ni nanoparticles. The rhodamine-6G sparse solution can be easily detected due to the large amount of hot spots. It has also been shown that such nanoparticles are quickly and simply manipulated by a magnetic field due to their nickel cores. Zhang et al. [12] applied nanoparticles in realistic applications and showed the differentiation of three different bacteria using $\mathrm{Fe}_{3} \mathrm{O}_{4}$-Au core-shell nanoparticles, and the signal was about 60 times higher than that obtained without a magnetic field.

Most bio-molecules vibrate in the infrared light, hence, infrared light is widely used in bio-sensing applications. Also, plasmonic nanoparticles surrounded by a catalyst are believed to improve the activities for the chemical transformations, e.g., by decreasing the chemical potential and increasing the number of free electrons. Both procedures increase the efficiency of decomposition reactions. Song et al. [13] provided an exhaustive investigation of the mechanism by which the photocatalytic reduction of carbon dioxide is achieved. The results revealed that the $\mathrm{CO}_{2}$ decomposition efficiency of $\mathrm{Au}-\mathrm{Pt}-\mathrm{SiO}_{2}$ nanoparticles was about twice as high compared to $\mathrm{Pt}-\mathrm{SiO}_{2}$ nanoparticles under the light intensity of $0.6\left(\mathrm{~W} / \mathrm{cm}^{2}\right)$; the efficiency of $\mathrm{Au}-\mathrm{Pt}-\mathrm{SiO}_{2}$ nanoparticles was found to be better than that of $\mathrm{Au}-\mathrm{SiO}_{2}$ and $\mathrm{Pt}-\mathrm{SiO}_{2}$ nanoparticles. Bora et al. [14] discussed the surface temperature of $\mathrm{Au}-\mathrm{ZnO}$ nanorods under resonant excitation up to about $300{ }^{\circ} \mathrm{C}$, which gave an apparent quantum yield (for the degradation of methylene blue) about 6 times higher than that achieved by bare $\mathrm{ZnO}$ nanorods. Mukherjee et al. [15] showed that the $\mathrm{H}_{2}$ dissociation can be achieved at room temperature due to the surface plasmon-induced hot electrons at the Au nanoparticle surface, as $\mathrm{H}_{2}$ has an extremely high dissociation energy $(4.51 \mathrm{eV})$.

The operation frequency is one of the most important factors influencing device efficiency. Some researchers have tuned the structure parameters of nanoparticles, as discussed above, to achieve the desired result. Instead of changing the morphology of the microstructures or nanostructures, one could focus on the optical properties of the selected materials, which are key parameters that strongly affect the plasmonic responses of materials. Different classes of materials have been explored, and they were found to depend on the operating wavelength of the applications. Some materials give a relatively low imaginary part of the permittivity as compared to metallic layers, such as graphene [16] 
or indium tin oxide $[17,18]$. Although graphene has been employed as a plasmonic material and has a negative real part of the permittivity under suitable operating conditions in the infrared light region, its magnitude of the real part of the permittivity is not so large and it gives a lower electric field enhancement on the surface of materials. To mitigate the loss of metallic materials (low imaginary part of permittivity) and maintain a relatively strong electric field enhancement (high magnitude of real part of permittivity), we propose a method of adding other components to obtain a hybrid alloy. The operating wavelength of a material can be adjusted with different atomic ratios for different applications. Silva et al. [19] gave the experimental and analytic data of $\mathrm{AuCu}$ alloy, which illustrated that the $\mathrm{AuCu}$ alloy possesses superior plasmonic properties from $500 \mathrm{~nm}$ to $690 \mathrm{~nm}$. Keast et al. [20] simulated a series of Au-based intermetallic materials ( $\mathrm{Al}, \mathrm{Cd}, \mathrm{Mg}, \mathrm{Pd}, \mathrm{Pt}, \mathrm{Sn}, \mathrm{Zn}, \mathrm{Zr}$ ) and discussed the localized surface plasmon properties of the materials. Gong et al. [21] synthesized alloys combining two out of $\mathrm{Au}, \mathrm{Ag}$, and $\mathrm{Cu}$, which give a tunable wavelength characteristic in the visible light region. The authors also mentioned that the permittivity of the alloys cannot be approximated by a simple linear combination of the dielectric function from the different metals making up the composition of the material. However, most of the strong plasmonic effects of noble metals occur in the visible region, which is dominated by interband transition. Blaber et al. [22] also stated that the partially occupied $\mathrm{d}$ bands of the alloy may affect the efficiency of its plasmonic effects, but the dopants may disrupt the low energy transition, which would in turn increase the plasmonic quality. Hence, the alloy may suitable for applications operating in the infrared region.

In this work, we explore the materials that will be potentially operated in the infrared region, and discuss Au-based and Pt-based noble metal alloys mixed with other six metals (Ir, Mo, Ni, Pb, Ta, $\mathrm{W})$. Au and Pt are widely used in the fields of plasmonics and catalysis. The permittivity of the noble metals supports a very good quality surface plasmon in the visible to infrared regions, and they are stable in normal environments. However, Au has a relatively low melting point $(1377 \mathrm{~K})$, while $\mathrm{Pt}$ has a slightly higher melting point $(2041 \mathrm{~K})$ but a rather high loss compared to Au. It is predicted that the melting point will increase when the alloy is combined with refractory metals such as Ir, Mo, $\mathrm{Ta}$, and W, whose melting points are $2739,2896,3290$, and $3698 \mathrm{~K}$, respectively. It is shown that the tensile strength of the alloys increases with the inclusion of Ir in PtIr [23]. Moreover, Ni-based alloys may also exhibit magnetic properties due to their ferromagnetic characteristic, and thus they will be useful in nano-bio applications. It is also predicted that the thermal stability of alloys will increase with the introduction of Ni. In addition to the transition metal, the poor metal is also discussed. Compared to the transition metals, the poor metals have a higher electronegativity, a lower melting point, and may be used in organic and biomolecule applications. $\mathrm{Pb}$ is one of the poor metals that is reported to show plasmonic properties in nanoparticles in the ultraviolent region [24]. In this work, we focus on the infrared optical properties of these unexplored alloys and discuss their potential to be used in infrared devices and systems. To investigate the optical responses of some practical nano objects, nanorods made of pure metals and different alloy materials are examined by finite-different time-domain simulations. These nanorods can be applied in high-temperature environments, localized surface plasmon polaritons, and catalysts. It should be noted that some of the alloys were found to have better plasmonic properties or magnetic properties than pure elemental metals, indicating the effectiveness of the alloying strategy for exploring high-performance infrared devices.

\section{Materials and Methods}

\subsection{Materials}

In this paper, we consider bi-metal alloys which are a combination of one noble metal and another metallic element. For the studied bi-metal alloys, the noble metal is $\mathrm{Au}$ or $\mathrm{Pt}$ and the other metallic element is $\mathrm{Ir}, \mathrm{Mo}, \mathrm{Ni}, \mathrm{Pb}, \mathrm{Ta}$, or $\mathrm{W}$ in our simulations. The simulated materials include 12 types of bi-metal alloys. The structures of the pure metallic materials in normal conditions are listed in Table 1. 
Table 1. Space group of the elements $\mathrm{Au}, \mathrm{Pt}, \mathrm{Ni}, \mathrm{Ir}, \mathrm{Pb}, \mathrm{Mo}$, Ta, and $\mathrm{W}$.

\begin{tabular}{ccc}
\hline Space Group & F3m3 & I3m3 \\
\hline Composition & $\mathrm{Au}, \mathrm{Pt}, \mathrm{Ir}, \mathrm{Ni}, \mathrm{Pb}$ & $\mathrm{Mo}, \mathrm{Ta}, \mathrm{W}$ \\
\hline
\end{tabular}

The crystal structure and electronic structure of the alloys are important factors influencing the alloys' material properties. Theoretically, it is predicted that the crystal structure of a bi-metal alloy remains the same as its constituted elements if the constituted elements have the same crystal structure. Boschow et al. [25] showed that $\mathrm{Au}_{92} \mathrm{Ni}_{8}$ exhibits the same space group, $\mathrm{F} 3 \mathrm{~m} 3$, as the constituent elements. However, some researchers have showed that the crystal structure can be reshaped and transformed into other crystal structure with an equal ratio of compositions and very different Bohr radii of elements. For example, Leroux [26] recorded the phase diagram of PtNi. It was shown that the crystal structure of PtNi alloy with an atomic ratio of around 0.5 is quite different from the crystal structures of Pt-rich or Ni-rich alloys. More complicated phase diagrams of bi-metal alloys can be found for constituted elements with two different structures. Ocken et al. [27] illustrated the phase diagram of PtMo from body-centered cubic (BCC) Mo to face-centered cubic (FCC) Pt. From the Inorganic Crystal Structure Database (ICSD [28]), it was shown that that AuTa alloy is of the F3m3 space group for $\mathrm{Au}_{0.9} \mathrm{Ta}_{0.1}$ but has a $\mathrm{CsCl}$ structure for $\mathrm{Au}_{0.5} \mathrm{Ta}_{0.5}$. For systematic discussions, we simulated the selected 12 alloys with $\mathrm{I} 3 \mathrm{~m} 3$ and $\mathrm{F} 3 \mathrm{~m} 3$ structures which may appear in nature. The snapshots of the $\mathrm{Pt}_{\mathrm{x}} \mathrm{Mo}_{(1-\mathrm{x})}$ F3m3 and I3m3 structures with different morphologies are shown in Figures 1 and 2, respectively.

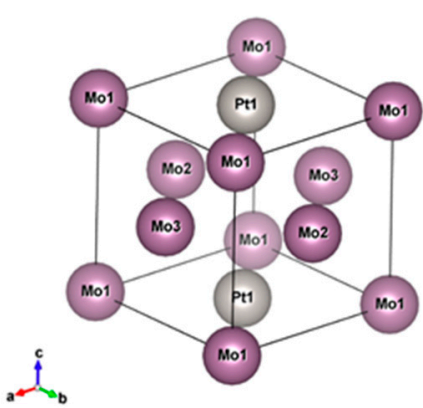

(a)

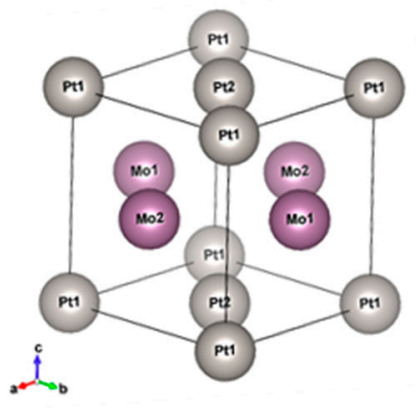

(b)

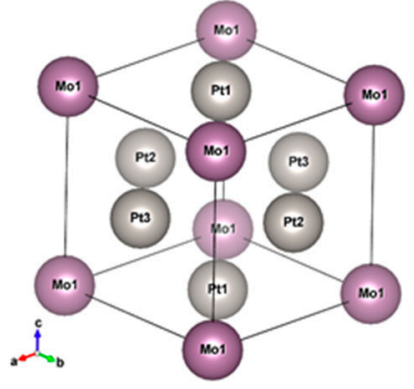

(c)

Figure 1. Snapshots of the $\mathrm{Pt}_{\mathrm{x}} \mathrm{Mo}_{(1-\mathrm{x})} \mathrm{F} 3 \mathrm{~m} 3$ structures with different morphologies: (a) $\mathrm{Pt}_{0.25} \mathrm{Mo}_{0.75}$, (b) $\mathrm{Pt}_{0.5} \mathrm{Mo}_{0.5}$ flat, and (c) $\mathrm{Pt}_{0.75} \mathrm{Mo}_{0.25}$.

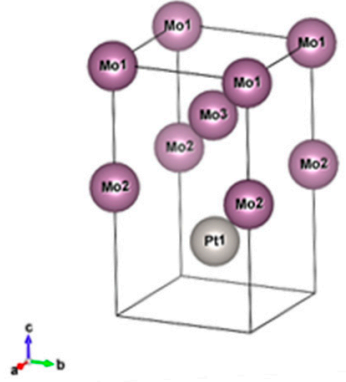

(a)

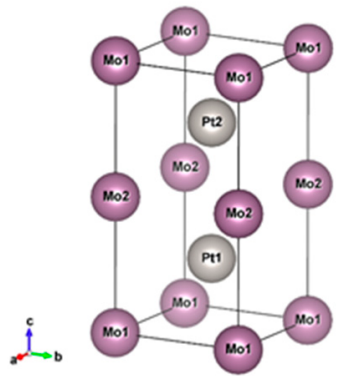

(b)

Figure 2. Cont. 


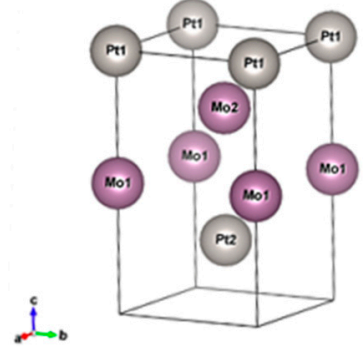

(c)

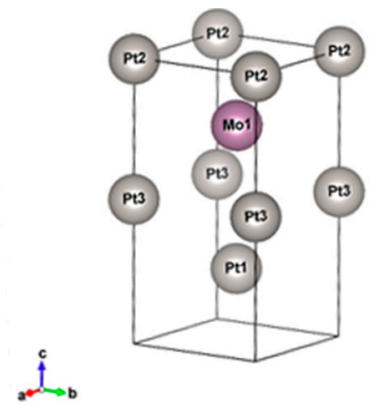

(d)

Figure 2. Snapshots of the $\mathrm{Pt}_{\mathrm{x}} \mathrm{Mo}_{(1-\mathrm{x})} \mathrm{I} 3 \mathrm{~m} 3$ structures with different morphologies: (a) $\mathrm{Pt}_{0.25} \mathrm{Mo}_{0.75}$, (b) $\mathrm{Pt}_{0.5} \mathrm{Mo}_{0.5} \_$mix, (c) $\mathrm{Pt}_{0.5} \mathrm{Mo}_{0.5} \_$upper, and (d) $\mathrm{Pt}_{0.75} \mathrm{Mo}_{0.25}$.

\subsection{Methods}

The results of the electronic structures of alloys were calculated using a plane wave basis with a cut-off energy of $450 \mathrm{eV}$ and the generalized gradient approximation (GGA) of the Perdew-Burke -Ernzerhof (PBE) [29] exchange correlation functional. The total energy was minimized by the quasi-Newton algorithm with a limitation of $0.0001 \mathrm{eV} / \AA$. Spin polarization was considered for nickel-containing alloys. The ground state was calculated with $10 \times 10 \times 10 \mathrm{k}$-points in momentum space. For optical permittivity calculation, a k-points grid of $50 \times 50 \times 50$ was chosen to ensure sufficient description for Brillouin zone. All k- points divisions are according to the Monkhorst-Pack method [30].

The finite-difference time-domain (FDTD, Lumericlal) calculations were performed to predict the optical responses of the bi-metal alloy nanorods. The wavelength-dependent dielectric response of alloys was calculated using density functional theory (DFT), and then used to evaluate the optical responses of a single nanorod. The light source was set as the plane wave, which has a polarization parallel to the nanorod. The mesh size was set as one order of magnitude smaller than the structure size.

\section{Pure Au}

The permittivity of bulk gold was first calculated and compared with the experimental data [31-39] to check the accuracy of the computation procedures. The permittivity was constructed by the interband and intraband contributions. The intraband is related to the behavior of the free electrons, which can be depicted by Drude's model. The real and imaginary parts of the intraband are expressed by Equations (1) and (2):

$$
\begin{gathered}
\operatorname{Re}\left[\varepsilon^{i n t r a}(\omega)\right]=1-\frac{\omega_{p}^{2}}{\omega^{2}+\Gamma^{2}} \\
\operatorname{Im}\left[\varepsilon^{\text {intra }}(\omega)\right]=\frac{\Gamma \omega_{p}^{2}}{\omega^{3}+\omega \Gamma^{2}}
\end{gathered}
$$

where $\omega_{p}$ represents the intraband free electron plasma frequency and $\Gamma$ is the damping frequency. In this paper, $\omega_{p}$ is calculated by DFT and $\Gamma$ is obtained from the experimental data or high accuracy simulation.

To determine the effect of $\Gamma$, we took $\mathrm{Au}$ as an example. In Table 2, the damping frequency is shown to fit Drude's model according to Blaber [40], Ordal [41], and Zeman [42]. For the comparisons, the damping frequency was calculated from 0.02 to $0.3 \mathrm{eV}$, and the experimental data of imaginary and real parts of dielectric constants are shown in Figure 3a,b. DF_Im. and DF_Re. along the $y$-axes in Figure 3 are denoted as the imaginary and real parts of the dielectric functions. It was found that the trend of Badar's data [31] which has a fitting parameter $\Gamma$ with a value of $0.0184 \mathrm{eV}$, is similar to the calculated case of $\Gamma$ equal to $0.02 \mathrm{eV}$. Zeman's [42] data was fitted by Hagemann's [32] experimental results which are located between 0.05 and $0.1 \mathrm{eV}$. Although Hagemann only provided experimental 
data under $826 \mathrm{~nm}$, the trend of this data is similar to that of our simulation data. Olmon et al. [35] discussed the relationship between the parameter $\Gamma$ and the permittivity of the different morphologies of gold in detail.

Table 2. Different damping frequency of gold reported by Blaber [40], Ordal [41], and Zeman [42].

\begin{tabular}{cccc}
\hline $\begin{array}{c}\text { Damping } \\
\text { Frequency (eV) }\end{array}$ & Blaber [40] & Ordal [41] & Zeman [42] \\
\hline $\mathrm{Au}$ & 0.0184 & 0.0267 & 0.0708 \\
\hline
\end{tabular}

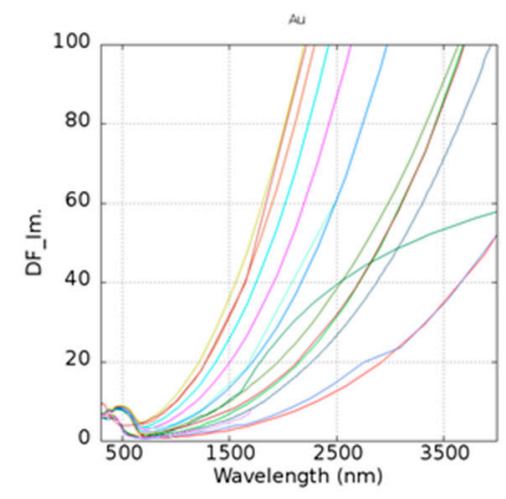

(a)

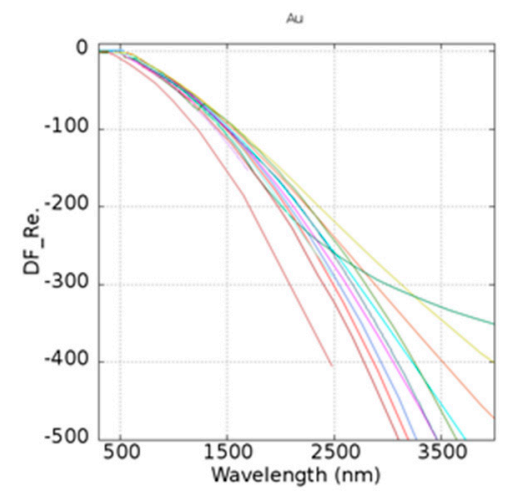

(b)

Figure 3. Testing of the damping frequency which varies from 0.02 to 0.3 in Au on (a) imaginary and (b) real parts of the permittivity. Different references [31-39] are plotted for comparison. DF_Im. and DF_Re. along the $y$-axes denote as the imaginary and real parts of the dielectric functions.

To excite the plasmons, the real part of the dielectric function should be negative to match the condition of the adjacent dielectric material. The parameter quality factor $(Q)$ is introduced to examine the performance of plasmons, and it is defined as Equation (3).

$$
Q=-\frac{\operatorname{Re}[\varepsilon(\omega)]}{\operatorname{Im}[\varepsilon(\omega)]}
$$

For a given material, a high $Q$ means that it has less loss and a stronger resonance property for inducing plasmons in this frequency range. The $Q$ of pure $A u$ is shown in Figure 4. The maximum of $Q$ is located at around $1100 \mathrm{~nm}$, which is consistent with the experimental data [31-39]. Most of the experimental data's $\Gamma$ are located between 0.02 and $0.1 \mathrm{eV}$. Considering the different metals employed in this work, the damping frequency is taken as $0.1 \mathrm{eV}$ for all systems except pure Au.

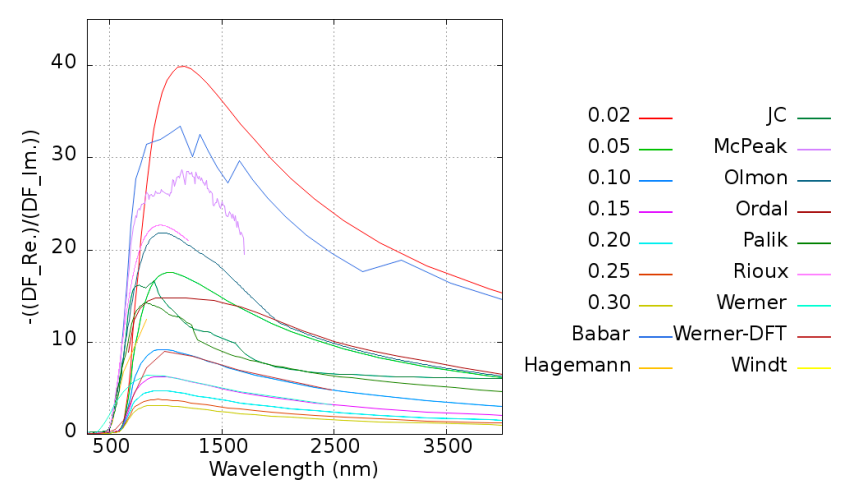

Figure 4. Quality factor versus wavelength for the damping frequency varying from 0.02 to $0.3 \mathrm{eV}$ for Au. The quality factors calculated from the dielectric constants obtained from different references [31-39] are plotted for comparison. 


\section{Au-Based Alloy}

The permittivity of alloys was calculated by combining the DFT calculated interband transition and Drude's term of intraband transition. To justify the calculated results, we took AuNi as an example. Jain et al. [43] reported an AuNi alloy wire generated by melting $99.99 \%$ pure nickel and gold ingot. It was predicted that the alloy atomic ratio would be 0.5 due to the vacuum system and repeated re-melting process. The quality factors of the AuNi from Jain's results were 0.575, 0.660, and 0.606 at 1000, 1500, and $2000 \mathrm{~nm}$ wavelengths, respectively. The trend of the quality factor was consistent with our data on $\mathrm{Au}_{0.5} \mathrm{Ni}_{0.5}$ (BCC_mix), which exhibited quality factors of $0.668,0.686$, and 0.682 at the same wavelengths.

To inspect the optical properties of alloys, we took $\mathrm{Au}_{x} \mathrm{Mo}_{(1-\mathrm{x})}$ alloy as an example. The imaginary and real parts of the permittivity of $\mathrm{Au}_{\mathrm{x}} \mathrm{Mo}_{(1-\mathrm{x})}$ alloy are shown in Figure $5 \mathrm{a}, \mathrm{b}$, respectively. In the legend of the plots in Figure 5, the first and the last ones characterize the pure metallic elements. The number represents the atomic ratio of $\mathrm{Au}$, while the text after the number denotes the structure and the morphology under the given atomic ratio condition. For example, 0.25_bcc represents $\mathrm{Au}_{0.25} \mathrm{Mo}_{0.75}$ with a BCC structure. In the $\mathrm{Au}_{\mathrm{x}} \mathrm{Mo}_{(1-\mathrm{x})}$ alloy, all cases possessed a higher imaginary part of the permittivity than pure $\mathrm{Au}$ and Mo above $1000 \mathrm{~nm}$. In addition to intraband transition, the interband transition also has the contribution to the imaginary part of the permittivity. Here, $\mathrm{Au}_{0.25} \mathrm{Mo}_{0.75}$ (FCC) was taken as an example for further discussion. The permittivity contributed by the interband transition of $\mathrm{Au}_{0.25} \mathrm{Mo}_{0.75}$ (FCC), pure $\mathrm{Au}$, and Mo is shown in Figure $5 \mathrm{c}$, and the corresponding density of states (DOS) is shown in Figure $5 \mathrm{~d}$. The DOS for each case is normalized by the maximum value within the range of -10 to $5 \mathrm{eV}$. It was shown that the onset of interband transition is roughly consistent with the distance between the large quantity states and the Fermi level. For instance, it was shown that the first huge DOS peak below the Fermi's level is around $2.5 \mathrm{eV}$ in the case of $\mathrm{Au}$ (Figure $5 \mathrm{~d}$, blue line), whereas the occurrence of interband transition is around $516 \mathrm{~nm}$. The combination of $\mathrm{Au}$ and Mo leads to additional states, which are known as the virtual states [20] and add the possibility of photon absorptions for the higher imaginary part of the permittivity.

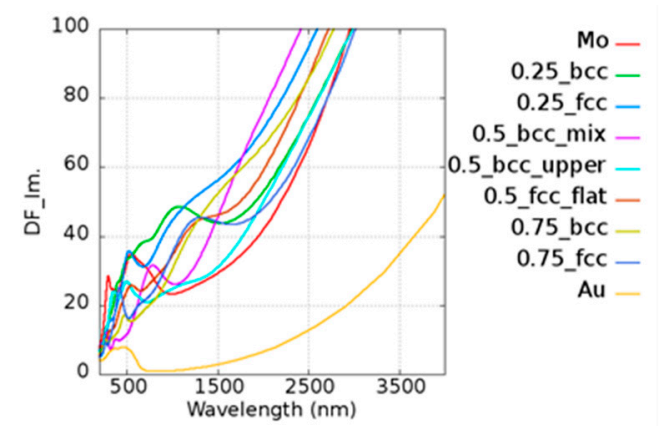

(a)

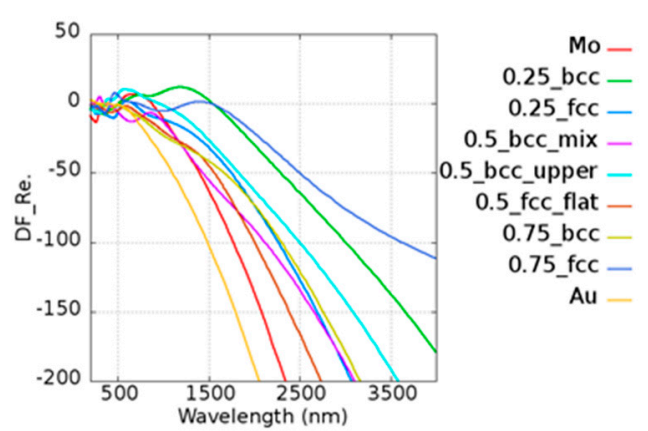

(b)

Figure 5. Cont. 


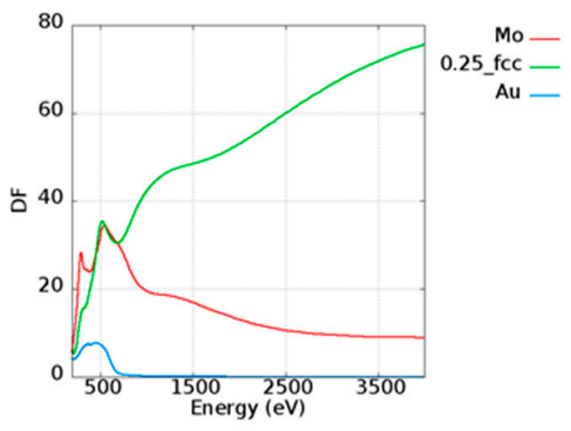

(c)

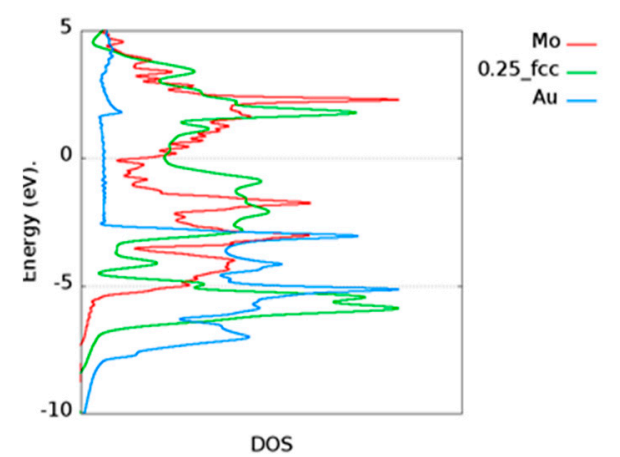

(d)

Figure 5. (a) Imaginary and (b) real parts of the permittivity of AuMo alloy. (c) The interband transition of the imaginary part of the permittivity and (d) the density of states of $\mathrm{Mo}, \mathrm{Au}_{0.25} \mathrm{Mo}_{0.75} \mathrm{FCC}$, and $\mathrm{Au}$. DF_Im. and DF_Re. along the $y$-axes denote the imaginary and real parts of the dielectric functions.

The results of $Q$ of the Au-based alloy are shown in Figure 6. In the legend of the plots, the first and the last ones characterize the pure metallic elements. The number represents the atomic ratio ofe $\mathrm{Au}$, while the text after the number denotes the structure and the morphology under the given atomic ratio condition. For example, in Figure 6a, 0.5_bcc_mix represents $\mathrm{Au}_{0.5} \mathrm{Ir}_{0.5} \_\mathrm{mix}$ with a BCC structure. The extreme high $Q$ of $A u$ is not fully shown here, although it is given in Figure 4. A material which has a $Q$ value lower than 1 may not be a good plasmonic material in such a frequency. Low- $Q$ materials occur around the visible region in most cases, and this contributes to the relatively high real part of the permittivity and the onset of interband transition. Some cases even serve as a dielectric material; in other words, they have a positive real part of the permittivity, as shown in the Appendix A. Although some alloys possess lower imaginary parts compared to pure metal, such as AuIr and AuNi, it was found that alloys have a larger real part of the permittivity due to the reduction of the plasma frequency. This leads to a larger intraband transition, as shown Equation (1), causing the shrinking of $Q$. Most of the cases exhibited a smaller $Q$ than pure metal, but there are still several instances that showed a good property of $Q$. For example, $A u_{0.25} \operatorname{Ir}_{0.75}$ and $A u_{0.75} \operatorname{Ir}_{0.25}$ had a better performance than pure metal at $600 \mathrm{~nm}$ and $800 \mathrm{~nm}$ of narrow band. The extremely low imaginary part of the permittivity of $\mathrm{Au}_{0.5} \mathrm{Ni}_{0.5}$ (FCC) was found even compared with other Au-based alloys and pure $\mathrm{Ni}$. The real and imaginary parts of permittivities of Au-based alloy are shown in Figure A1 of Appendix A. It is not surprising that $\mathrm{Au}_{0.5} \mathrm{Ni}_{0.5}$ (FCC) showed a good performance above $3500-4000 \mathrm{~nm}$. $A_{0.5} \mathrm{~W}_{0.5}$ (BCC_mix) possessed a better $Q$ performance than pure $\mathrm{W}$ around the near-infrared region at $1000 \mathrm{~nm}$. On the other hand, manufacturing costs may be reduced by using different compositions. The prices of $\mathrm{Au}, \mathrm{Pt}$, and $\mathrm{Ir}$ remained in same order in 2018, being more expensive than $\mathrm{Ni}, \mathrm{Mo}, \mathrm{Pb}, \mathrm{Ta}$, and $\mathrm{W}$. The raw material cost may be an important issue affecting the mass production of devices. The $Q$ performance was larger than 1 in most of the Au-based alloys in the infrared region, indicating that these may be used in different applications. 


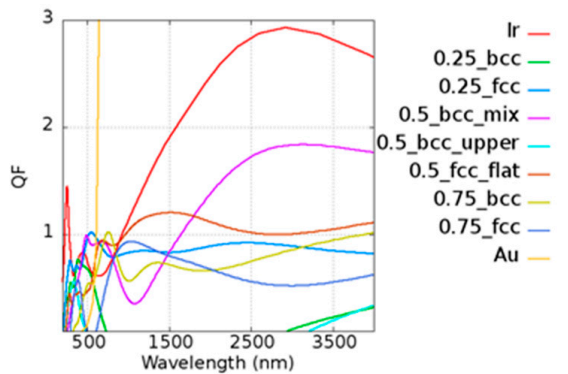

(a)

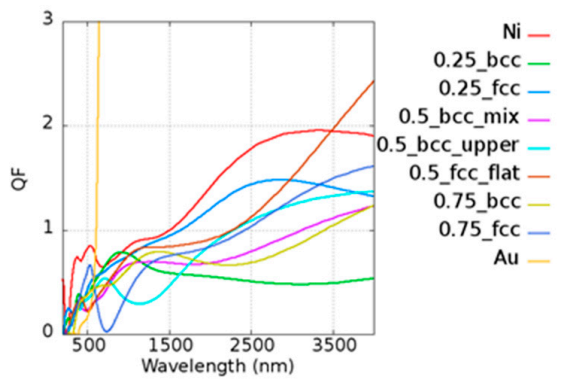

(c)

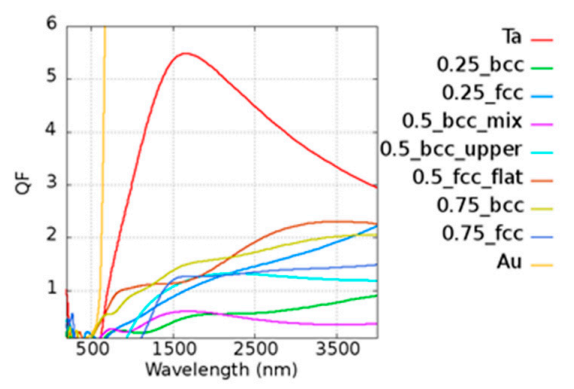

(e)

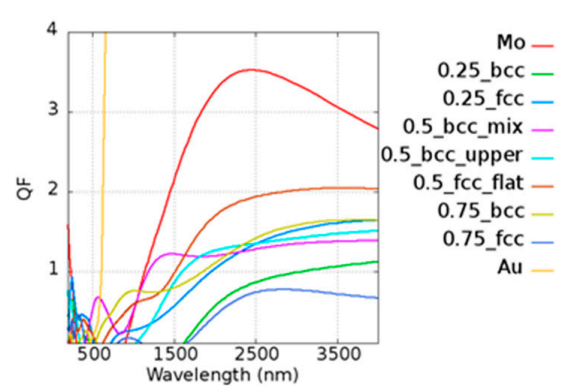

(b)

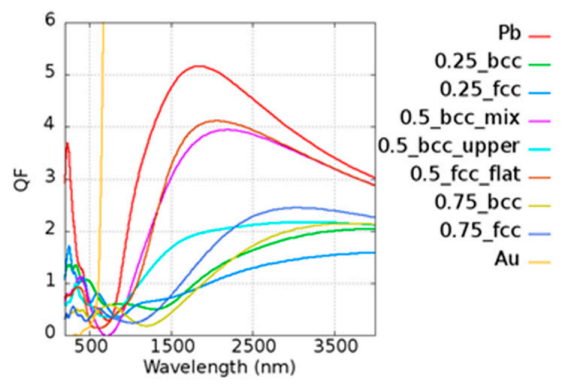

(d)

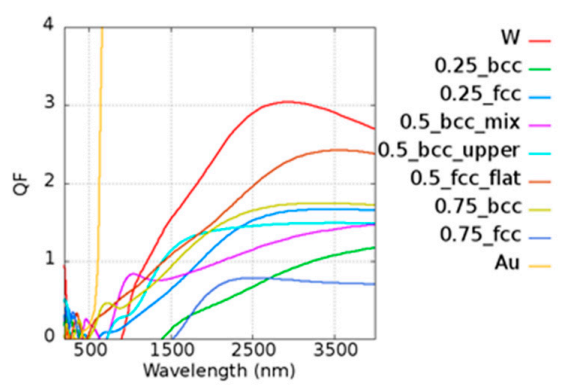

(f)

Figure 6. Quality factors of (a) $\mathrm{Au}_{\mathrm{x}} \mathrm{Ir}_{(1-\mathrm{x})}$, (b) $\mathrm{Au}_{\mathrm{x}} \mathrm{Mo}_{(1-\mathrm{x})}$, (c) $\mathrm{Au}_{\mathrm{x}} \mathrm{Ni}_{(1-\mathrm{x})}$, (d) $\mathrm{Au}_{\mathrm{x}} \mathrm{Pb}_{(1-\mathrm{x})}$, (e) $\mathrm{Au}_{\mathrm{x}} \mathrm{Ta}_{(1-\mathrm{x})}$, and (f) $\mathrm{Au}_{\mathrm{x}} \mathrm{W}_{(1-\mathrm{x})}$ alloys.

\section{Pt-Based Alloy}

Unlike pure $\mathrm{Au}, \mathrm{Pt}$ has a smaller $Q$ due to its high imaginary part of the permittivity. The results of $Q$ of Pt-based alloy are shown in Figure 7. In the legend of the plots, the first and the last ones characterize the pure metallic elements. The number represents the atomic ratio of $\mathrm{Au}$, while the text after the number denotes the structure and the morphology under the given atomic ratio condition. For example, in Figure 7a, 0.75_fcc represents $\mathrm{Au}_{0.75} \mathrm{Ir}_{0.25}$ with an FCC structure. $\mathrm{Pt}_{0.5} \operatorname{Ir}_{0.5}\left(\mathrm{BCC} \_\mathrm{mix}\right)$ and $\mathrm{Pt}_{0.75} \mathrm{Ir}_{0.25}$ (BCC) had stronger plasmonic responses in the visible range of 600 to $700 \mathrm{~nm}$ as compared to pure $\mathrm{Pt}$. $\mathrm{Pt}_{0.75} \mathrm{Mo}_{0.25}$ (BCC_mix) exhibited a higher $Q$ in the range of 900 to $1300 \mathrm{~nm}$, which contributes to the lower loss and similar real part of pure Pt. The real and imaginary parts of permittivities of $\mathrm{Pt}$-based alloy are shown in Figure $\mathrm{A} 2$ of Appendix $\mathrm{A}$. $\mathrm{Pt}_{0.75} \mathrm{Ni}_{0.25}$ (BCC) could be applied in the range of 600 to $1000 \mathrm{~nm}$ and $\mathrm{Pt}_{0.25} \mathrm{Ni}_{0.75}$ (FCC) had a similar $Q$ to that of two pure metals in the range of 2400 to $2700 \mathrm{~nm}$. $\mathrm{Pt}_{0.25} \mathrm{~Pb}_{0.75}$ (FCC) and $\mathrm{Pt}_{0.5} \mathrm{~Pb}_{0.5}$ (BCC_upper) exhibited better results above $2750 \mathrm{~nm}$ compared to pure $\mathrm{Pt}_{\text {. }} \mathrm{Pt}_{0.5} \mathrm{Ta}_{0.5}$ (BCC_mix) was good at visible range, and $\mathrm{Pt}_{0.5} \mathrm{Ta}_{0.5}$ (BCC_upper) and $\mathrm{Pt}_{0.5} \mathrm{Ta}_{0.5}$ (BCC_flat) could be applied above 2700 and $2000 \mathrm{~nm}$, respectively. $\mathrm{Pt}_{0.5} \mathrm{Ta}_{0.5}$ (BCC_mix) had a high $Q$ in the broad band of 600 to $1400 \mathrm{~nm}$. Pt was found to be a good candidate for catalysis, as mentioned in the previous discussions. It was shown that some alloys possess better 
performances than pure Pt. According to our simulation results, the design of the material used in devices may be adjusted in different applications in consideration of the cost and the performance.

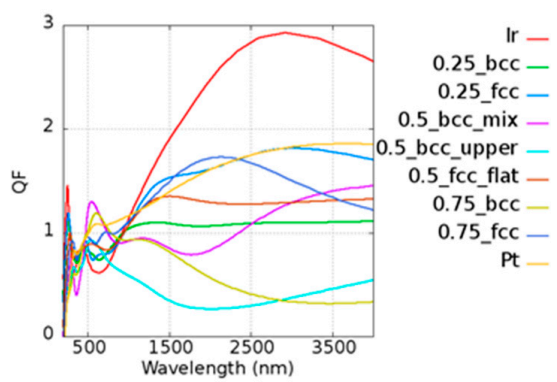

(a)

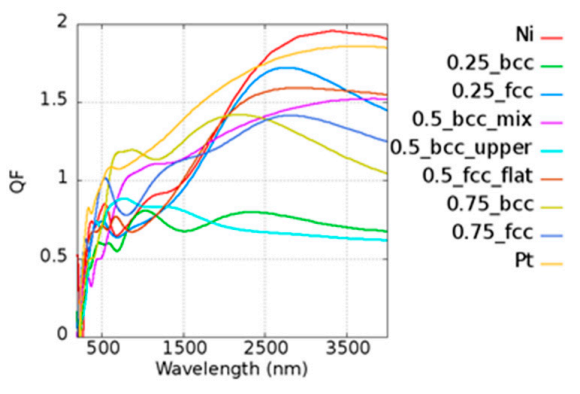

(c)

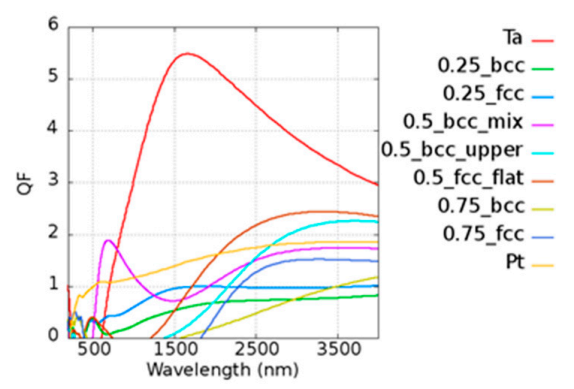

(e)

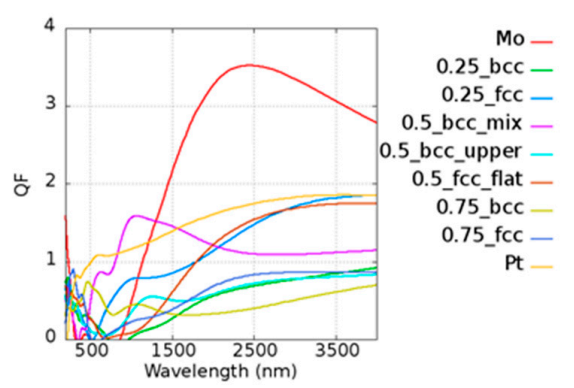

(b)

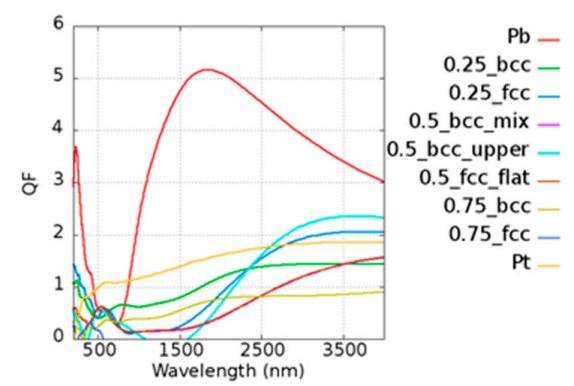

(d)

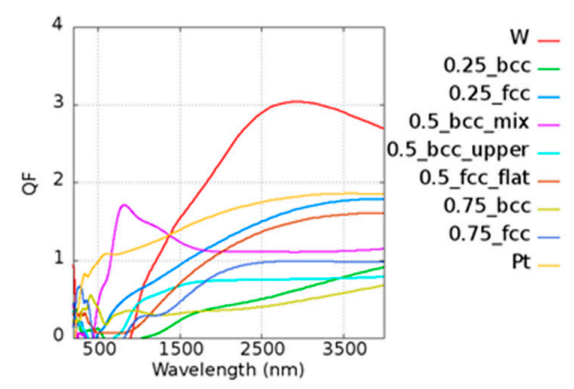

(f)

Figure 7. Quality factors of (a) $\operatorname{Pt}_{\mathrm{x}} \mathrm{Ir}_{(1-\mathrm{x})}$, (b) $\mathrm{Pt}_{\mathrm{x}} \mathrm{Mo}_{(1-\mathrm{x})}$, (c) $\mathrm{Pt}_{\mathrm{x}} \mathrm{Ni}_{(1-\mathrm{x})}$, (d) $\mathrm{Pt}_{\mathrm{x}} \mathrm{Pb}_{(1-\mathrm{x})},(\mathbf{e}) \mathrm{Pt}_{\mathrm{x}} \mathrm{Ta}_{(1-\mathrm{x})}$, and (f) $\mathrm{Pt}_{\mathrm{x}} \mathrm{W}_{(1-\mathrm{x})}$ alloys.

\section{Discussions}

Most of the cases exhibited fine performances as $Q>1$ in the infrared frequency, which indicated the good applicability of most alloys. It was found that $Q$ was approximated to be inversely proportional to the frequency in the infrared frequency region because it is dominated by the motion of free electron according to the Drude model, as the incident photon energy is low in the infrared region.

For the applications of magnetic plasmonics, the ferromagnetic metal $\mathrm{Ni}$ was alloyed with $\mathrm{Au}$ and Pt. Our calculated optical property of $\mathrm{Au}_{0.75} \mathrm{Ni}_{0.25}$ has the similar trend as compared to the experimental data by using dual magnetron sputtering to deposit the metallic alloy thin film from Mcpherson et al. [44]. Lonergan et al. [45] studied the effect of different ratios of $\mathrm{Pt}_{\mathrm{x}} \mathrm{Ni}_{(1-\mathrm{x})}$ on benzene hydrogenation, and it was shown that $\mathrm{Ni}$ in alloy strengthens the bond formation which increases the activity of catalysts. The magnetic moments of $\mathrm{Au}_{x} \mathrm{Ni}_{(1-\mathrm{x})}$ and $\mathrm{Pt}_{\mathrm{x}} \mathrm{Ni}_{(1-\mathrm{x})}$ alloy are listed in Table 3. As the content of $\mathrm{Ni}$ increases, the magnetic moment rises. However, a trade-off between plasmonic properties and magnetic properties was observed, except that FCC $\mathrm{Au}_{0.5} \mathrm{Ni}_{0.5}$ exhibited 
better characteristics than pure $\mathrm{Ni}$ around 3000 to $4000 \mathrm{~nm}$, which may indicate its potential as a magnetic plasmonic material.

Table 3. Magnetic moments of AuNi and PtNi with different ratios and morphologies.

\begin{tabular}{|c|c|c|c|c|c|}
\hline $\begin{array}{l}\text { Magnetic } \\
\text { Moment }\end{array}$ & 0 & 0.25 & 0.5 & 0.75 & 1 \\
\hline $\mathrm{Au}_{\mathrm{x}} \mathrm{Ni}_{(1-\mathrm{x})}$ & 0.617 & $\begin{array}{l}1.573(\mathrm{BCC}) \\
1.551 \text { (FCC) }\end{array}$ & $\begin{array}{c}0.496 \text { (BCC_mix) } \\
0.960 \text { (BCC_upper) } \\
0.726 \text { (FCC) }\end{array}$ & $\begin{array}{l}0.006(\mathrm{BCC}) \\
0.012(\mathrm{FCC})\end{array}$ & 0 \\
\hline $\mathrm{Pt}_{\mathrm{x}} \mathrm{Ni}_{(1-\mathrm{x})}$ & 0.617 & $\begin{array}{l}2.240(\mathrm{BCC}) \\
2.246(\mathrm{FCC})\end{array}$ & $\begin{array}{c}0.705 \text { (BCC_mix) } \\
1.370 \text { (BCC_upper) } \\
2.179 \text { (FCC) }\end{array}$ & $\begin{array}{c}-0.001 \\
(\mathrm{BCC}) \\
1.043(\mathrm{FCC})\end{array}$ & 0 \\
\hline
\end{tabular}

It has been reported that PtMo is suitable for use in fuel cells due to its greater stability compared to that of pure Pt. Pt cathodes suffer from oxidation and a loss of active surface area. It was shown that the alloy cathode had a lighter material loss when $\mathrm{CO}$ was present in the fuel stream. The PtMo alloy nanoparticles were reported by Liu [46], who successfully mitigated the contamination of the anode electrocatalysts. Ehteshami et al. [47] also showed the identical trend that PtMo had a better performance than pure Pt. It is worth mentioning that PtNi has also been reported in the literature. It was shown that the bimetallic alloy is more stable than a monometallic material in some cases, making it more suitable for catalytic and thermal applications.

\section{Optical Responses of Nanorods}

To further investigate the optical responses of some practical nano objects, the electromagnetic fields of nanorods made of different materials were examined. In this part, we mainly focused on the effect of the material; therefore, the nanorods were simulated. The influence of the gaps between adjacent nanoraods or the density of nanorods was neglected.

First, to confirm the results of FDTD with the experimental data from Takahashi et al. [48], a gold nanorod with a length varying from 60 to $70 \mathrm{~nm}$ with an interval of $5 \mathrm{~nm}$ and a radius of $11 \mathrm{~nm}$ was simulated. The absorbance of gold nanorods is shown in Figure 8, revealing peaks located at 830, 850, and $950 \mathrm{~nm}$ for nanorod lengths of 60,65 , and $70 \mathrm{~nm}$, respectively. Because a single gold nanorod was considered in this simulation, the extreme narrow peak is shown, which is the ideal case of the pure gold nanorod. It is easy to explain that the broadened peak of the experimental data [48] is simply due to the size distribution of the nanorods. On the other hand, the wavelength tunability is clearly shown, indicating that the absorbance peak increased as the nanorod length increased. The intensity was also strengthened with length, which give a quite intuitive explanation of absorbing more energy. The results were consistent with the experimental data [48], showing an absorbance peak located at 800 to $1100 \mathrm{~nm}$.

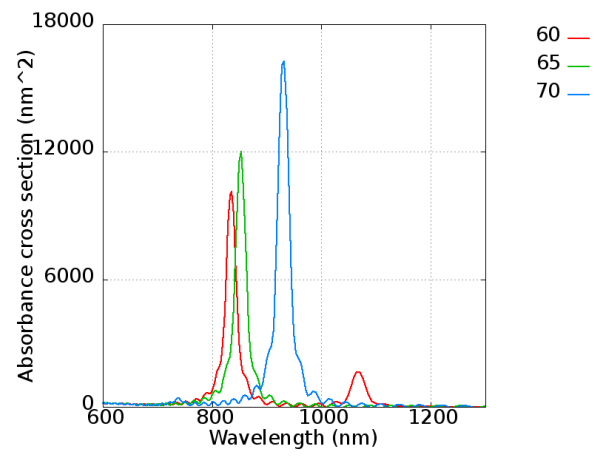

Figure 8. Absorbance cross-sections of the gold nanorods with different nanorod lengths of 60, 65, and $70 \mathrm{~nm}$. 
The simulated results of the alloy nanorods with a length of $100 \mathrm{~nm}$ and a diameter of $11 \mathrm{~nm}$ which have cross-section areas of approximately $1480 \mathrm{~nm}^{2}$ are shown in Figure 9, including $\mathrm{AuNi}, \mathrm{AuPb}$, $\mathrm{PtNi}$, and $\mathrm{PtPb}$. Combining the two materials, the trend of the absorbance cross-section was consistent with the $Q$ values. For example, in the AuPb case, the sequence of $Q$ intensity above $1000 \mathrm{~nm}$ was $\mathrm{Au}$, $\mathrm{Pb}, \mathrm{Au}_{0.5} \mathrm{~Pb}_{0.5}$ (FCC_flat), and $\mathrm{Au}_{0.5} \mathrm{~Pb}_{0.5}$ (BCC_mix), etc. However, the nanorod peak absorbance was confined to a small region due to the structure effect of the nanorods. The extreme narrow peak of $\mathrm{Au}$ is shown, illustrating its high sensitivity. On the other hand, Pt had a strong absorbance in the visible and infrared light regions, Ni showed quite a broad band from 500 to $1300 \mathrm{~nm}$, and $\mathrm{Pb}$ possessed two main peaks at around 490 and $1100 \mathrm{~nm}$. The broad band absorbance of $\mathrm{Ni}$ and $\mathrm{Pb}$ contributed to the additional absorption in the alloy above $2000 \mathrm{~nm}$ compared to the pure metal, which may be applied in the lower energy region. In Au-based alloy nanorods, the better plasmonic performance of alloy was demonstrated compared to pure $\mathrm{Au}$ in the visible region. The other better performance was shown in the infrared region around 1300 to $1400 \mathrm{~nm}$ in all cases compared to Au. It is worth mentioning that the relative narrow bands of $\mathrm{Au}_{0.5} \mathrm{~Pb}_{0.5}$ (FCC_flat), $\mathrm{Au}_{0.5} \mathrm{~Pb}_{0.5}$ (FCC_upper), and $\mathrm{Au}_{0.5} \mathrm{~Pb}_{0.5}$ (BCC_mix) were found and that all peaks were situated in a similar frequency This could reduce the difficulty in synthesis by allowing some ambiguity in stoichiometry. Peak shifting was shown in most cases except for PtIr and PtNi. Due to the analogous electromagnetic response of $\mathrm{Pt}$, $\mathrm{Ir}$, and $\mathrm{Ni}$, the alloys of these metals maintain similar operation wavelengths of 700 to $1100 \mathrm{~nm}$. These alloys can be well designed by tuning their structure parameters for suitable frequency. On the contrary, the wavelength selective absorbance is shown, which may be utilized for different applications in different operation frequency ranges.

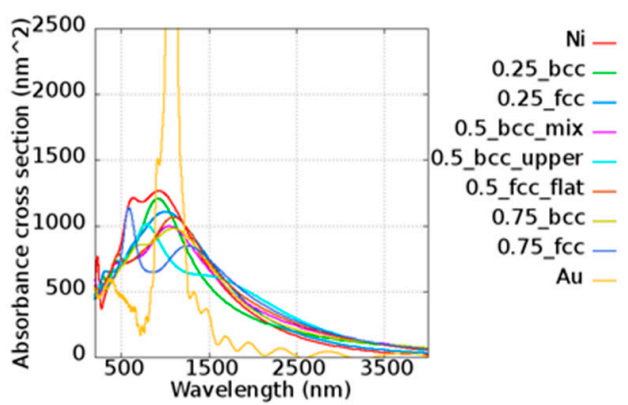

(a)

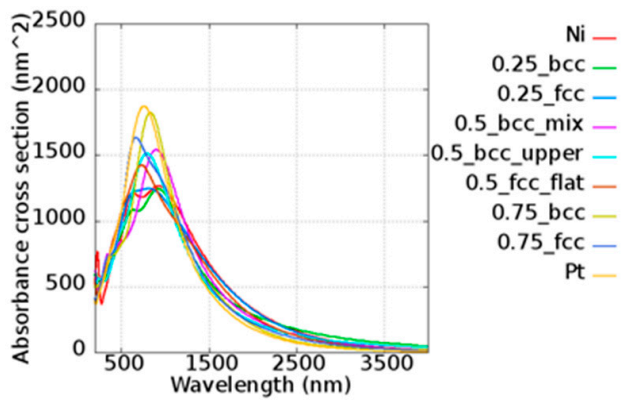

(c)

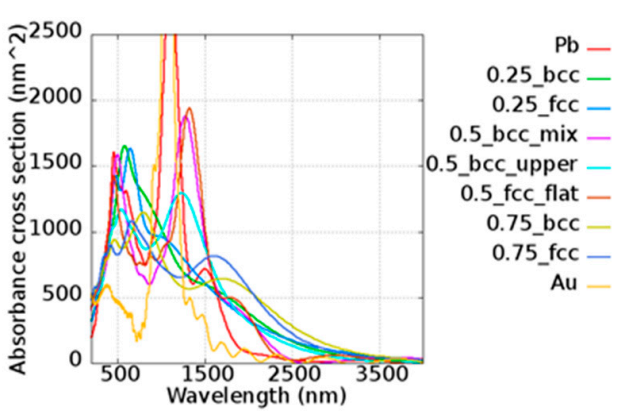

(b)

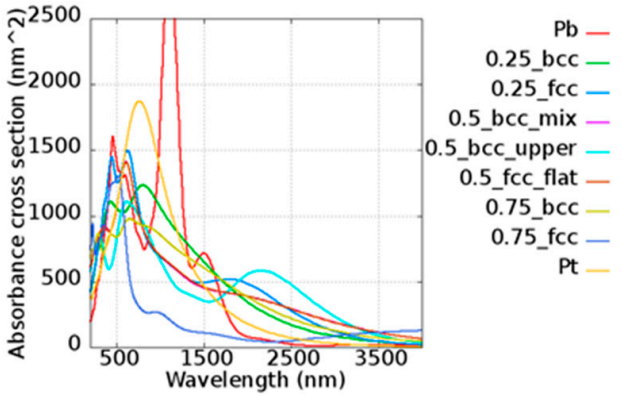

(d)

Figure 9. Absorbance cross-sections of the (a) AuNi, (b) AuPb, (c) PtNi, and (d) PtPb nanorods with a length of $100 \mathrm{~nm}$ and a radius of $11 \mathrm{~nm}$.

The tunable absorbances of nanorods were consisted with the aspect ratio, as demonstrated in many reports [49-51]. The nanorod was lengthened to be $350 \mathrm{~nm}$ whereas the diameter was maintained at $11 \mathrm{~nm}$. Upon increasing the aspect ratio to the value of 31.81, the absorbance cross-sections of AuNi, 
$\mathrm{AuPb}, \mathrm{PtNi}$, and PtPb varied, as shown in Figure 10. The absorbance peak shifted to around $3000 \mathrm{~nm}$. The absorbance cross-sections of all alloy nanorods possessed a much larger area than the area cross-sections of about $5329.34 \mathrm{~nm}^{2}$ around the wavelength of $3000 \mathrm{~nm}$. This indicates that these alloy nanorods are suitable for application in the infrared range. Effects of the wavelength tunability and associated amplification were found in different alloys. This illustrates that the compositions of two elements can be well adjusted to access different absorbance features.

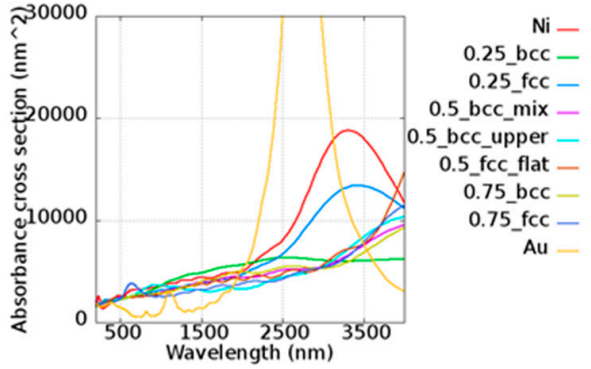

(a)

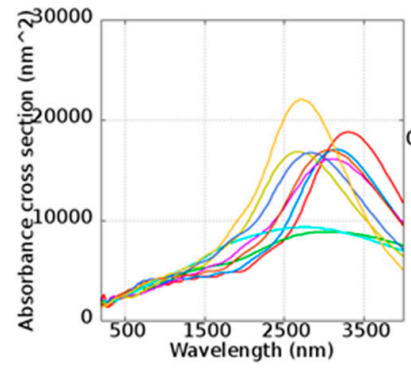

(c)

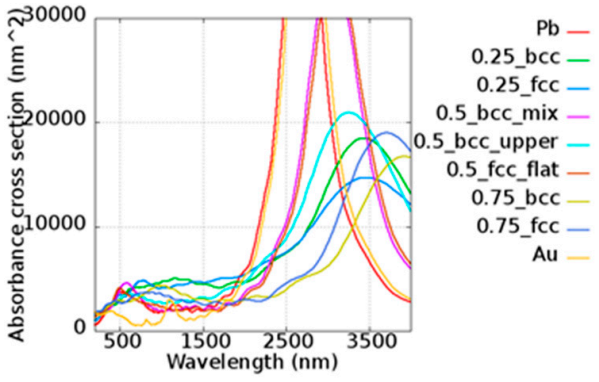

(b)

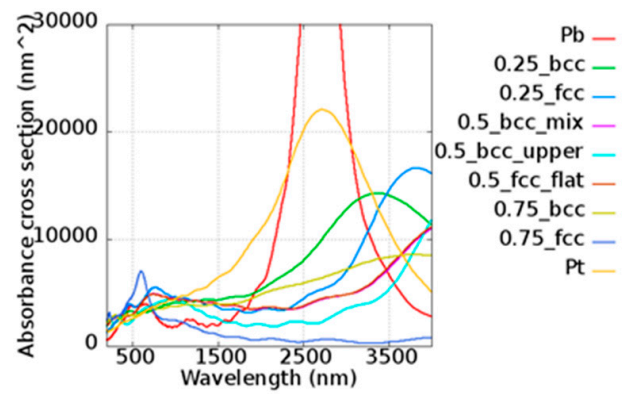

(d)

Figure 10. Absorbance cross-sections of the (a) AuNi, (b) $\mathrm{AuPb},(\mathbf{c}) \mathrm{PtNi}$, and (d) PtPb nanorods with a length of $350 \mathrm{~nm}$ and a radius of $11 \mathrm{~nm}$.

\section{Conclusions}

In this work, the dielectric functions of Au- and Pt-based alloys were examined by DFT simulation, and then adopted in the absorbance calculations of alloy nanorods by FDTD simulations. The plasmonic performances of bulk devices were inspected by their quality factors. Most of the alloys were found to be suitable for use in the infrared region for certain compositions and would be useful for thermal emitters and infrared sensors which can be further employed in MEMS-based systems and micromachines. Furthermore, some of the alloy exhibited better performances in the infrared region compared to pure elemental metals, which is rarely seen for cases in the visible region. Pt-based alloys possessed a similar quality factor $Q$ as that of pure metal in the infrared region, which may indicate their potential for replacing $\mathrm{Pt}$ in some catalytic applications. FDTD simulations for nanorods were demonstrated to examine the optical responses of these alloys. Wavelength selective properties were shown in most cases from the visible to the infrared region. The nanorods of different alloys could be applied in high-temperature environments, localized surface plasmon polaritions, and catalysts, with considering their $Q$ performances at particular wavelengths and manufacturing cost. This work provides a method for designing suitable alloys for infrared devices.

Author Contributions: M.-H.C., J.-H.L. and T.N. gave the concepts of this paper; M.-H.C. performed the simulations; J.-H.L. analyzed the data; M.-H.C., J.-H.L. and T.N. investigated the alloy properties; M.-H.C. and J.-H.L. conceived and designed the simulations; M.-H.C., J.-H.L. and T.N. wrote the paper. 
Acknowledgments: This work was partially supported by the Ministry of Science and Technology (104-2221-E-002-079-MY3 and 107-2918-I-002-020) and the NTU Project (107L7829). We are grateful to the National Center for High-Performance Computing, Taiwan, for providing us with the computation time and facilities. This work was also partially supported by JSPS KAKENHI (16F16315, JP16H06364, 16H03820) and CREST “Phase Interface Science for Highly Efficient Energy Utilization” (JPMJCR13C3) from Japan Science and Technology Agency.

Conflicts of Interest: The authors declare no conflict of interest.

\section{Appendix A}

The permittivity of the Au-based alloy and that of the Pt-based alloy are shown in Figures A1 and A2, respectively. The left-hand column is the imaginary part of the permittivity and the right-hand column is real part of the permittivity.

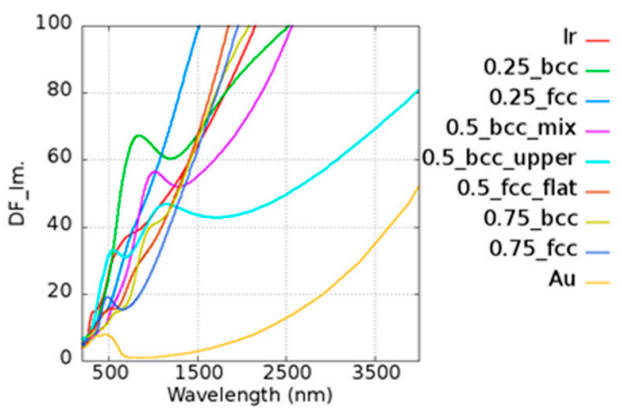

(a)

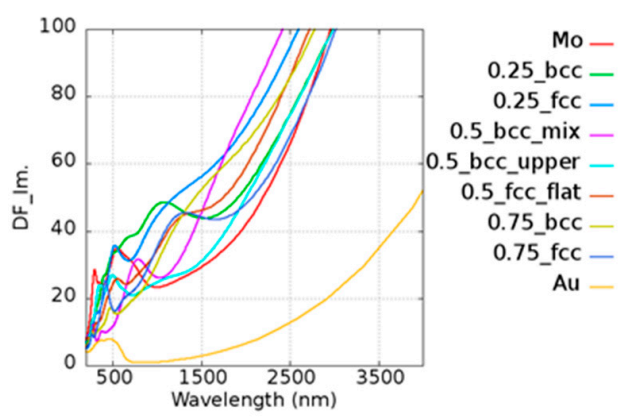

(c)

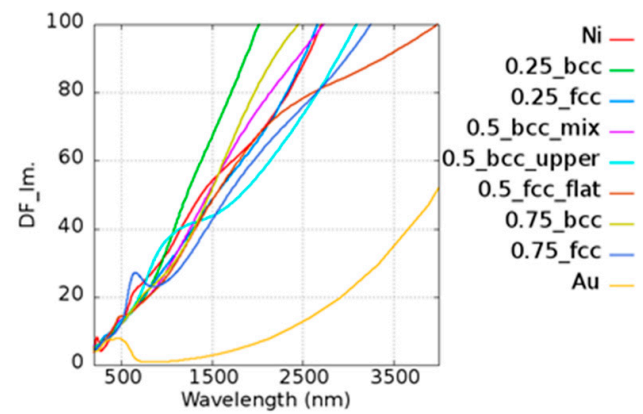

(e)

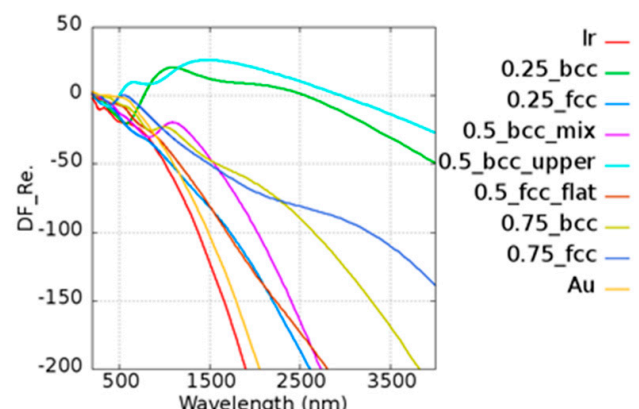

(b)

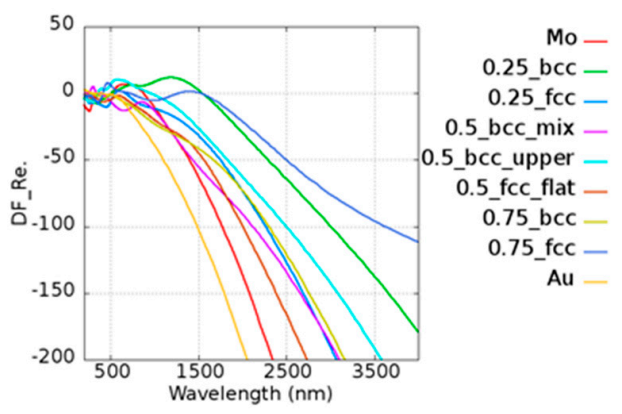

(d)

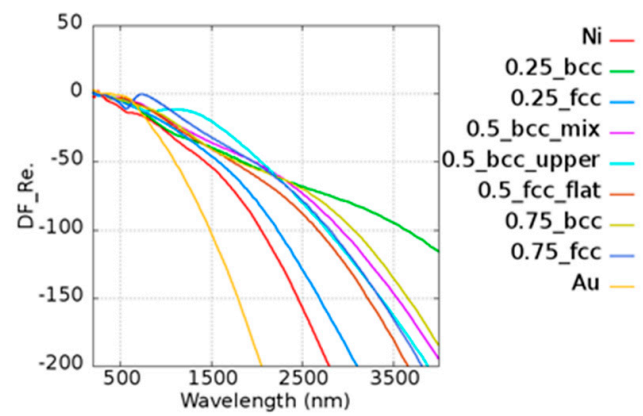

(f)

Figure A1. Cont. 


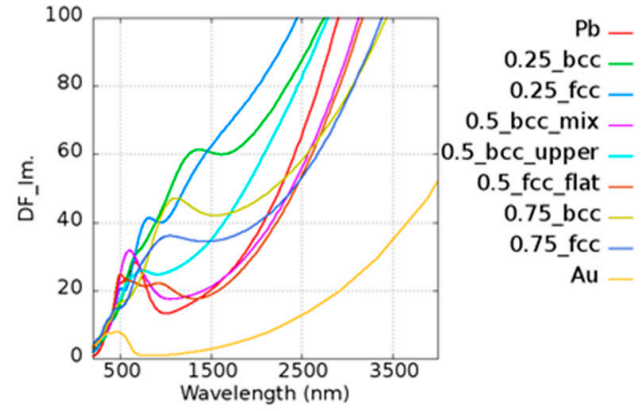

(g)

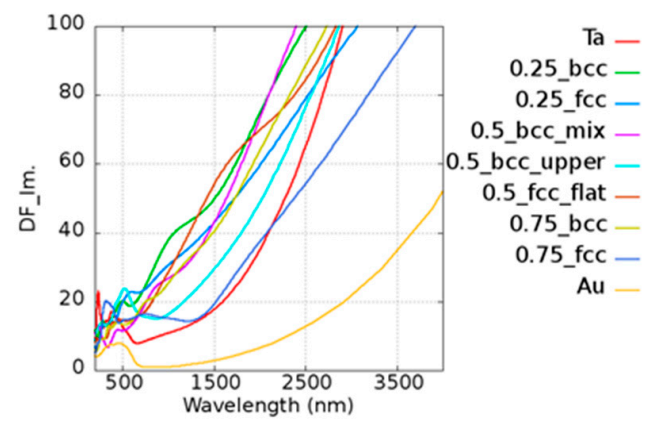

(i)

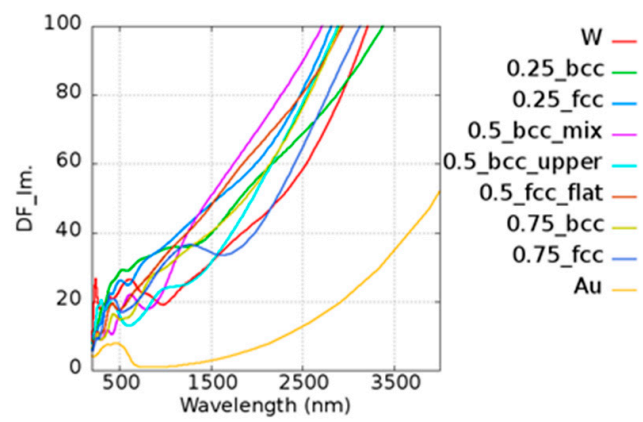

(k)

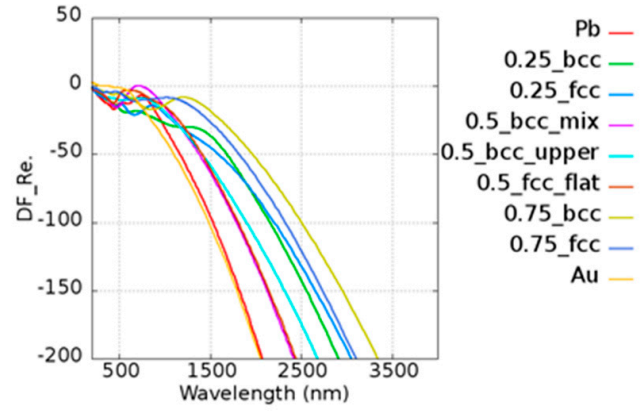

(h)

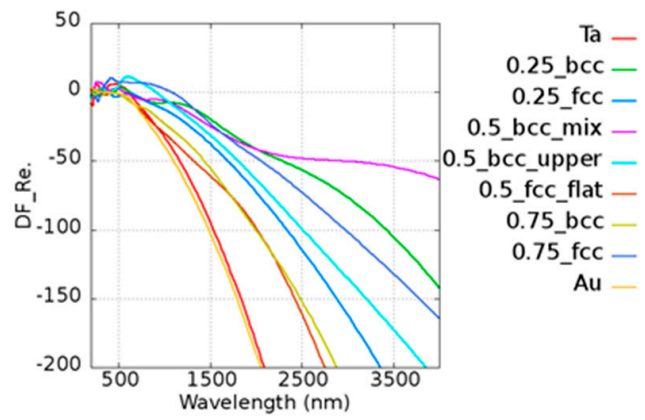

(j)

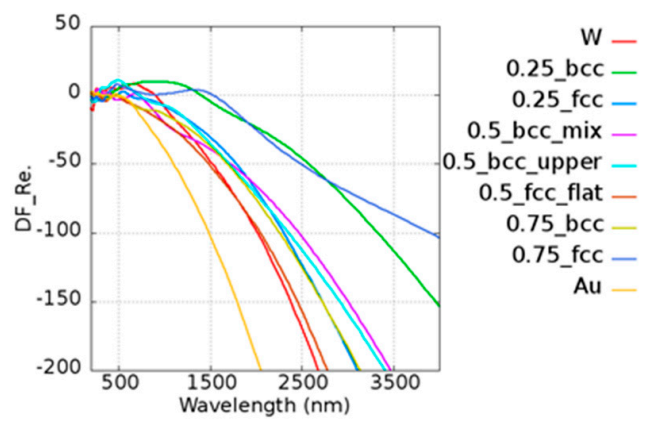

(1)

Figure A1. Imaginary and real parts of the permittivity of (a,b) AuIr, (c,d) AuMo, (e,f) AuNi, (g,h) AuPb, $(\mathbf{i}, \mathbf{j})$ AuTa, and (k,1) AuW. DF_Im. and DF_Re. along the $y$-axes denote the imaginary and real parts of the dielectric functions. 


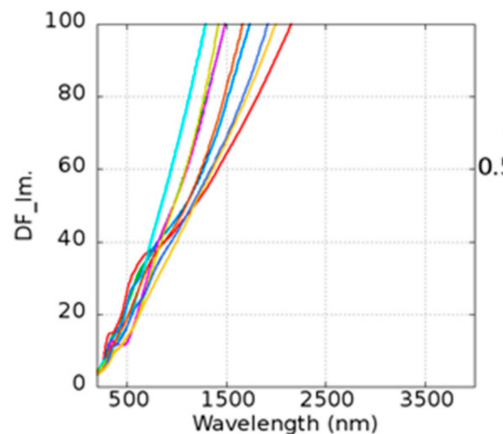

(a)

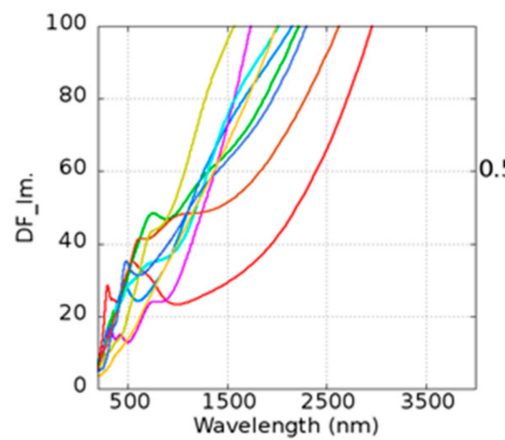

(c)

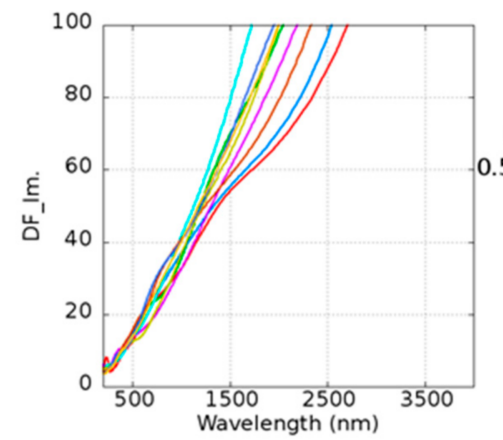

$0.25 \mathrm{Ni}-$

$0.25 \mathrm{fcc}-$

0.5 bcc_mix 0.5 bcc_upper -

0.5 ffc_flat

0.75 bcc

0.75 fcc

$\mathrm{Pt}$

(e)

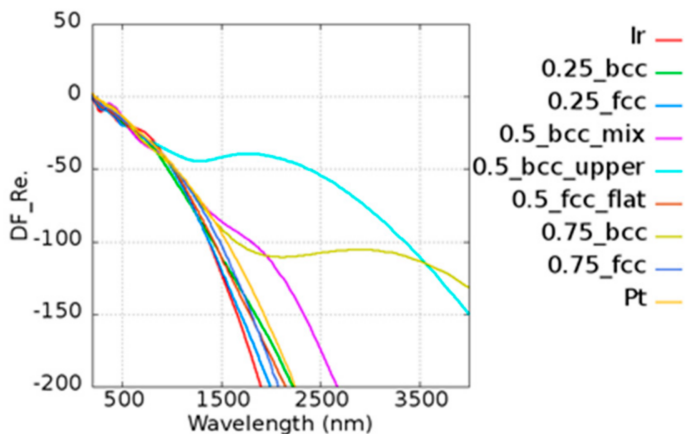

(b)

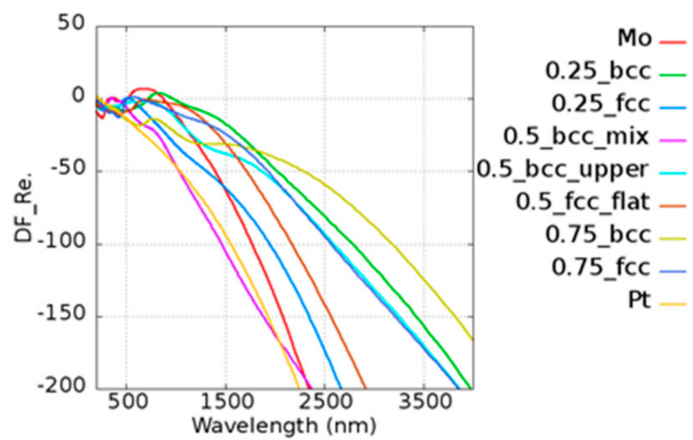

(d)

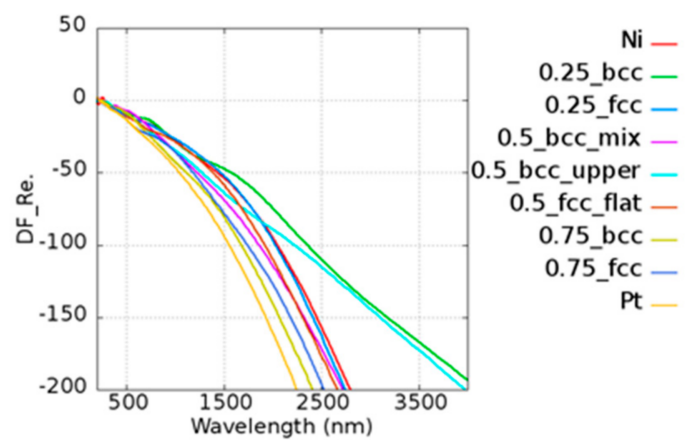

(f)

Figure A2. Cont. 


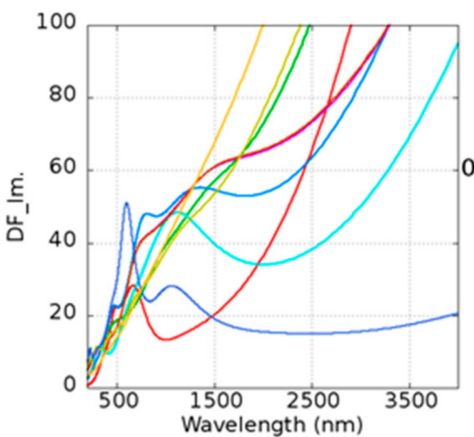

(g)
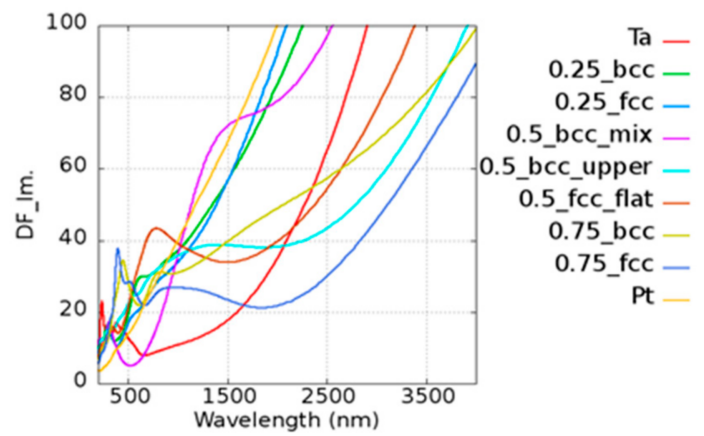

(i)

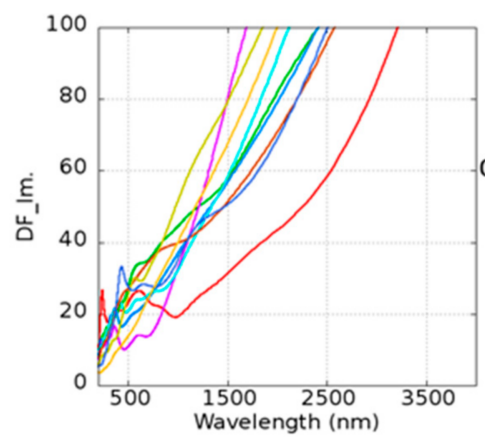

W-

0.25 bcc

0.25 fcc -

0.5 bcc_mix -

0.5 bcc_upper -

0.5 fcc flat -

0.75 bcc

0.75 fcc

Pt -

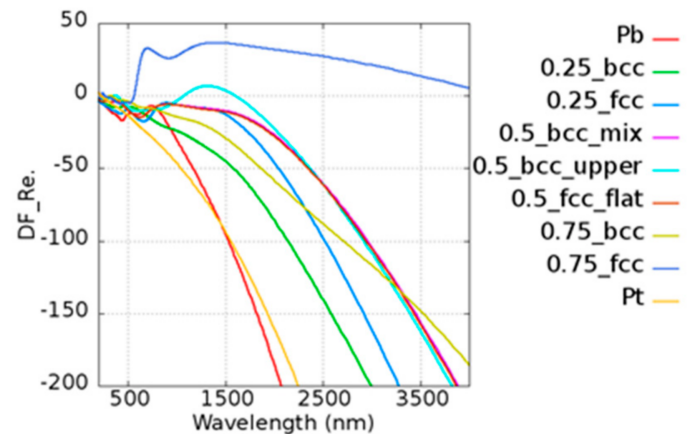

(h)

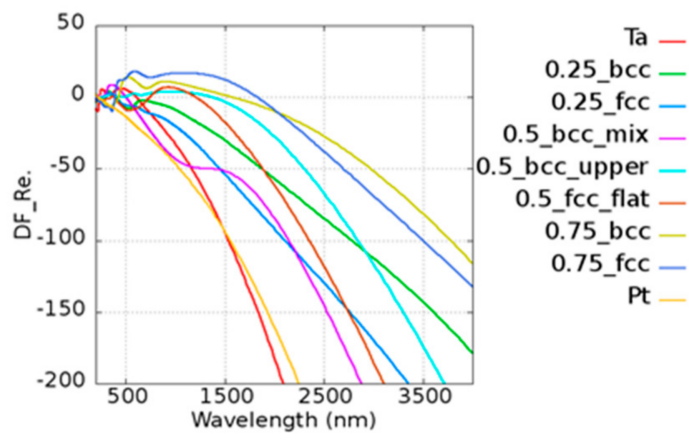

(j)

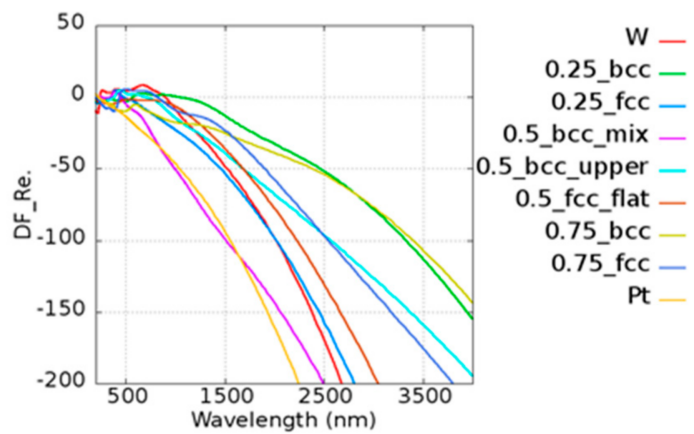

(1)

Figure A2. Imaginary and real parts of the permittivity of (a,b) PtIr, (c,d) PtMo, (e,f) PtNi, (g,h) PtPb, $(\mathbf{i}, \mathbf{j})$ PtTa, and $(\mathbf{k}, \mathbf{l})$ PtW. DF_Im. and DF_Re. along the $y$-axes denote the imaginary and real parts of the dielectric functions. 


\section{References}

1. Dao, T.D.; Chen, K.; Ishii, S.; Ohi, A.; Nabatame, T.; Kitajima, M.; Nagao, T. Infrared perfect absorbers fabricated by colloidal mask etching of $\mathrm{Al}-\mathrm{Al}_{2} \mathrm{O}_{3}-\mathrm{Al}$ trilayers. ACS Photonics 2015, 2, 964-970. [CrossRef]

2. Yang, Z.-Y.; Ishii, S.; Yokoyama, T.; Dao, T.D.; Sun, M.-G.; Pankin, P.S.; Timofeev, I.V.; Nagao, T.; Chen, K.-P. Narrowband wavelength selective thermal emitters by confined tamm plasmon polaritons. ACS Photonics 2017, 4, 2212-2219. [CrossRef]

3. Yokoyama, T.; Dao, T.D.; Chen, K.; Ishii, S.; Sugavaneshwar, R.P.; Kitajima, M.; Nagao, T. Spectrally selective mid-infrared thermal emission from molybdenum plasmonic metamaterial operated up to $1000 \mathrm{C}$. Adv. Opt. Mater. 2016, 4, 1987-1992. [CrossRef]

4. Reddy, H.; Guler, U.; Kudyshev, Z.; Kildishev, A.V.; Shalaev, V.M.; Boltasseva, A. Temperature-dependent optical properties of plasmonic titanium nitride thin films. ACS Photonics 2017, 4, 1413-1420. [CrossRef]

5. Kaur, M.; Ishii, S.; Shinde, S.L.; Nagao, T. All-ceramic microfibrous solar steam generator: TiN plasmonic nanoparticle-loaded transparent microfibers. ACS Sustain. Chem. Eng 2017, 5, 8523-8528. [CrossRef]

6. Sugavaneshwar, R.P.; Ishii, S.; Dao, T.D.; Ohi, A.; Nabatame, T.; Nagao, T. Fabrication of highly metallic TiN films by pulsed laser deposition method for plasmonic applications. ACS Photonics 2017, 5, 814-819. [CrossRef]

7. Bansal, A.; Verma, S. Optical response of noble metal alloy nanostructures. Phys. Lett. A 2015, 379, $163-169$. [CrossRef]

8. Dodson, S.; Haggui, M.; Bachelot, R.; Plain, J.; Li, S.; Xiong, Q. Optimizing electromagnetic hotspots in plasmonic bowtie nanoantennae. J. Phys. Chem. Lett. 2013, 4, 496-501. [CrossRef]

9. Brullot, W.; Valev, V.K.; Verbiest, T. Magnetic-plasmonic nanoparticles for the life sciences: Calculated optical properties of hybrid structures. Nanomed. Nanotechnol. Biol. Med. 2012, 8, 559-568. [CrossRef]

10. Kwizera, E.A.; Chaffin, E.; Shen, X.; Chen, J.; Zou, Q.; Wu, Z.; Gai, Z.; Bhana, S.; O'Connor, R.; Wang, L. Size-and shape-controlled synthesis and properties of magnetic-plasmonic core-shell nanoparticles. J. Phys. Chem. C 2016, 120, 10530-10546. [CrossRef]

11. Liu, D.; Wang, X.; He, D.; Dao, T.D.; Nagao, T.; Weng, Q.; Tang, D.; Wang, X.; Tian, W.; Golberg, D. Magnetically Assembled Ni@Ag Urchin-Like Ensembles with Ultra-Sharp Tips and Numerous Gaps for SERS Applications. Small 2014, 10, 2564-2569. [CrossRef] [PubMed]

12. Zhang, L.; Xu, J.; Mi, L.; Gong, H.; Jiang, S.; Yu, Q. Multifunctional magnetic-plasmonic nanoparticles for fast concentration and sensitive detection of bacteria using SERS. Biosens. Bioelectron. 2012, 31, 130-136. [CrossRef] [PubMed]

13. Song, H.; Meng, X.; Dao, T.D.; Zhou, W.; Liu, H.; Shi, L.; Zhang, H.; Nagao, T.; Kako, T.; Ye, J. Light-Enhanced Carbon Dioxide Activation and Conversion by Effective Plasmonic Coupling Effect of Pt and Au Nanoparticles. ACS Appl. Mater. Interfaces 2017, 10, 408-416. [CrossRef] [PubMed]

14. Bora, T.; Zoepfl, D.; Dutta, J. Importance of plasmonic heating on visible light driven photocatalysis of gold nanoparticle decorated zinc oxide nanorods. Sci. Rep. 2016, 6, 26913. [CrossRef] [PubMed]

15. Mukherjee, S.; Libisch, F.; Large, N.; Neumann, O.; Brown, L.V.; Cheng, J.; Lassiter, J.B.; Carter, E.A.; Nordlander, P.; Halas, N.J. Hot electrons do the impossible: Plasmon-induced dissociation of H2 on Au. Nano Lett. 2012, 13, 240-247. [CrossRef] [PubMed]

16. Xiao, T.-H.; Cheng, Z.; Goda, K. Graphene-on-silicon hybrid plasmonic-photonic integrated circuits. Nanotechnology 2017, 28, 245201. [CrossRef] [PubMed]

17. Chen, C.; Wang, Z.; Wu, K.; Chong, H.; Xu, Z.; Ye, H. ITO-TiN-ITO Sandwiches for Near-Infrared Plasmonic Materials. ACS Appl. Mater. Interfaces 2018, 10, 14886-14893. [CrossRef]

18. Franzen, S. Surface plasmon polaritons and screened plasma absorption in indium tin oxide compared to silver and gold. J. Phys. Chem. C 2008, 112, 6027-6032. [CrossRef]

19. De Silva, K.; Gentle, A.; Arnold, M.; Keast, V.; Cortie, M. Dielectric function and its predicted effect on localized plasmon resonances of equiatomic Au-Cu. J. Phys. D Appl. Phys. 2015, 48, 215304. [CrossRef]

20. Keast, V.J.; Barnett, R.L.; Cortie, M. First principles calculations of the optical and plasmonic response of Au alloys and intermetallic compounds. J. Phys. Condens. Matter 2014, 26, 305501. [CrossRef]

21. Gong, C.; Kaplan, A.; Benson, Z.A.; Baker, D.R.; McClure, J.P.; Rocha, A.R.; Leite, M.S. Band Structure Engineering by Alloying for Photonics. Adv. Opt. Mater. 2018, 1800218. [CrossRef] 
22. Blaber, M.G.; Arnold, M.D.; Ford, M.J. A review of the optical properties of alloys and intermetallics for plasmonics. J. Phys. Condens. Matter 2010, 22, 143201. [CrossRef] [PubMed]

23. Rakhtsaum, G. Platinum alloys: A selective review of the available literature. Platin. Met. Rev. 2013, 57, 202-213. [CrossRef]

24. McMahon, J.M.; Schatz, G.C.; Gray, S.K. Plasmonics in the ultraviolet with the poor metals Al, Ga, In, Sn, Tl, $\mathrm{Pb}$, and Bi. Phys. Chem. Chem. Phys. 2013, 15, 5415-5423. [CrossRef] [PubMed]

25. Buschow, K.V.; Van Engen, P.; Jongebreur, R. Magneto-optical properties of metallic ferromagnetic materials. J. Magn. Magn. Mater. 1983, 38, 1-22. [CrossRef]

26. Leroux, C.; Cadeville, M.; Pierron-Bohnes, V.; Inden, G.; Hinz, F. Comparative investigation of structural and transport properties of L10 NiPt and CoPt phases; the role of magnetism. J. Phys. F Met. Phys. 1988, 18, 2033. [CrossRef]

27. Ocken, H.; Van Vucht, J. Phase equilibria and superconductivity in the molybdenum-platinum system. J. Less Common Met. 1968, 15, 193-199. [CrossRef]

28. Hellenbrandt, M. The inorganic crystal structure database (ICSD)_Present and future. Crystallogr. Rev. 2004, 10, 17-22. [CrossRef]

29. Perdew, J.P.; Burke, K.; Ernzerhof, M. Generalized gradient approximation made simple. Phys. Rev. Lett. 1996, 77, 3865. [CrossRef]

30. Monkhorst, H.J.; Pack, J.D. Special points for Brillouin-zone integrations. Phys. Rev. B 1976, 13, 5188. [CrossRef]

31. Babar, S.; Weaver, J. Optical constants of Cu, Ag, and Au revisited. Appl. Opt. 2015, 54, 477-481. [CrossRef]

32. Hagemann, H.-J.; Gudat, W.; Kunz, C. Optical constants from the far infrared to the x-ray region: $\mathrm{Mg}, \mathrm{Al}, \mathrm{Cu}$, $\mathrm{Ag}, \mathrm{Au}, \mathrm{Bi}, \mathrm{C}$, and $\mathrm{Al}_{2} \mathrm{O}_{3}$. JOSA 1975, 65, 742-744. [CrossRef]

33. Johnson, P.B.; Christy, R.-W. Optical constants of the noble metals. Phys. Rev. B 1972, 6, 4370. [CrossRef]

34. McPeak, K.M.; Jayanti, S.V.; Kress, S.J.; Meyer, S.; Iotti, S.; Rossinelli, A.; Norris, D.J. Plasmonic films can easily be better: Rules and recipes. ACS Photonics 2015, 2, 326-333. [CrossRef] [PubMed]

35. Olmon, R.L.; Slovick, B.; Johnson, T.W.; Shelton, D.; Oh, S.-H.; Boreman, G.D.; Raschke, M.B. Optical dielectric function of gold. Phys. Rev. B 2012, 86, 235147. [CrossRef]

36. Philipp, H.; Palik, E.D. Handbook of Optical Constants of Solids; Palik, E.D., Ed.; Academic: Orlando, FL, USA, 1985; Volume 749, p. 74.

37. Rioux, D.; Vallieres, S.; Besner, S.; Muñoz, P.; Mazur, E.; Meunier, M. An analytic model for the dielectric function of Au, Ag, and their alloys. Adv. Opt. Mater. 2014, 2, 176-182. [CrossRef]

38. Werner, W.S.; Glantschnig, K.; Ambrosch-Draxl, C. Optical constants and inelastic electron-scattering data for 17 elemental metals. J. Phys. Chem. Ref. Data 2009, 38, 1013-1092. [CrossRef]

39. Windt, D.L.; Cash, W.C.; Scott, M.; Arendt, P.; Newnam, B.; Fisher, R.; Swartzlander, A. Optical constants for thin films of Ti, Zr, Nb, Mo, Ru, Rh, Pd, Ag, Hf, Ta, W, Re, Ir, Os, Pt, and Au from $24 \AA$ to $1216 \AA$. Appl. Opt. 1988, 27, 246-278. [CrossRef]

40. Blaber, M.; Arnold, M.; Ford, M. Designing materials for plasmonic systems: The alkali-noble intermetallics. J. Phys. Condens. Matter 2010, 22, 095501. [CrossRef]

41. Ordal, M.A.; Bell, R.J.; Alexander, R.W.; Newquist, L.A.; Querry, M.R. Optical properties of Al, Fe, Ti, Ta, W, and Mo at submillimeter wavelengths. Appl. Opt. 1988, 27, 1203-1209. [CrossRef]

42. Zeman, E.J.; Schatz, G.C. An accurate electromagnetic theory study of surface enhancement factors for silver, gold, copper, lithium, sodium, aluminum, gallium, indium, zinc, and cadmium. J. Phys. Chem. 1987, 91, 634-643. [CrossRef]

43. Jain, C.; Tuniz, A.; Reuther, K.; Wieduwilt, T.; Rettenmayr, M.; Schmidt, M.A. Micron-sized gold-nickel alloy wire integrated silica optical fibers. Opt. Mater. Express 2016, 6, 1790-1799. [CrossRef]

44. McPherson, D.J.; Supansomboon, S.; Zwan, B.; Keast, V.J.; Cortie, D.L.; Gentle, A.; Dowd, A.; Cortie, M.B. Strategies to control the spectral properties of Au-Ni thin films. Thin Solid Films 2014, 551, 200-204. [CrossRef]

45. Lonergan, W.W.; Vlachos, D.G.; Chen, J.G. Correlating extent of Pt-Ni bond formation with low-temperature hydrogenation of benzene and 1, 3-butadiene over supported Pt/Ni bimetallic catalysts. J. Catal. 2010, 271, 239-250. [CrossRef]

46. Liu, Z.; Hu, J.E.; Wang, Q.; Gaskell, K.; Frenkel, A.I.; Jackson, G.S.; Eichhorn, B. PtMo Alloy and MoO x@ Pt Core-Shell Nanoparticles as Highly CO-Tolerant Electrocatalysts. J. Am. Chem. Soc. 2009, 131, 6924-6925. [CrossRef] [PubMed] 
47. Ehteshami, S.M.M.; Jia, Q.; Halder, A.; Chan, S.; Mukerjee, S. The role of electronic properties of Pt and Pt alloys for enhanced reformate electro-oxidation in polymer electrolyte membrane fuel cells. Electrochim. Acta 2013, 107, 155-163. [CrossRef]

48. Takahashi, H.; Niidome, Y.; Niidome, T.; Kaneko, K.; Kawasaki, H.; Yamada, S. Modification of gold nanorods using phosphatidylcholine to reduce cytotoxicity. Langmuir 2006, 22, 2-5. [CrossRef] [PubMed]

49. Jain, P.K.; Lee, K.S.; El-Sayed, I.H.; El-Sayed, M.A. Calculated absorption and scattering properties of gold nanoparticles of different size, shape, and composition: Applications in biological imaging and biomedicine. J. Phys. Chem. B 2006, 110, 7238-7248. [CrossRef]

50. Gao, J.; Bender, C.M.; Murphy, C.J. Dependence of the gold nanorod aspect ratio on the nature of the directing surfactant in aqueous solution. Langmuir 2003, 19, 9065-9070. [CrossRef]

51. Link, S.; Mohamed, M.; El-Sayed, M. Simulation of the optical absorption spectra of gold nanorods as a function of their aspect ratio and the effect of the medium dielectric constant. J. Phys. Chem. B 1999, 103, 3073-3077. [CrossRef]

(C) 2019 by the authors. Licensee MDPI, Basel, Switzerland. This article is an open access article distributed under the terms and conditions of the Creative Commons Attribution (CC BY) license (http://creativecommons.org/licenses/by/4.0/). 